\title{
Evaluate the role of organic acids in the protection of ligands from radiolytic degradation
}

Fuel Cycle Technology

Prepared for

U.S. Department of Energy Material Recovery and Waste Form Development Anneka Miller, Stephen Mezyk, Dean Peterman Idaho National Laboratory August 31, 2016 FCRD-MRWFD-2016-000318 



\section{DISCLAIMER}

This information was prepared as an account of work sponsored by an agency of the U.S. Government. Neither the U.S. Government nor any agency thereof, nor any of their employees, makes any warranty, expressed or implied, or assumes any legal liability or responsibility for the accuracy, completeness, or usefulness, of any information, apparatus, product, or process disclosed, or represents that its use would not infringe privately owned rights. References herein to any specific commercial product, process, or service by trade name, trade mark, manufacturer, or otherwise, does not necessarily constitute or imply its endorsement, recommendation, or favoring by the U.S. Government or any agency thereof. The views and opinions of authors expressed herein do not necessarily state or reflect those of the U.S. Government or any agency thereof. 



\section{SUMMARY}

In the Advanced TALSPEAK process, the bis(2-ethylhexyl)phosphoric acid (HDEHP) extractant used in the traditional TALSPEAK process is replaced by the extractant 2-ethylhexylphosphonic acid mono-2-ethylhexyl ester (HEH[EHP]). In addition, the aqueous phase complexant and buffer used in traditional TALSPEAK is replaced with the combination of $\mathrm{N}$-(2-hydroxyethyl)ethylenediamineN,N',N'-triacetic acid (HEDTA) and citric acid. In order to evaluate the possible impacts of gamma radiolysis upon the efficacy of the Advanced TALSPEAK flowsheet, aqueous and organic phases corresponding to the extraction section of the proposed flowsheet were irradiated in the INL test loop under an ambient atmosphere.

The results of these studies conducted at INL, led INL researchers to conclude that the scarcity of values of rate constants for the reaction of hydroxyl radical with the components of the Advanced TALSPEAK process chemistry was severely limiting the interpretation of the results of radiolysis studies performed at the INL. In this work, the rate of reaction of hydroxyl radical with citric acid at several $\mathrm{pH}$ values was measured using a competitive pulse radiolysis technique. The results reported here demonstrate the importance of obtaining hydroxyl radical reaction rate data for the conditions that closely resemble actual solution conditions expected to be used in an actual solvent extraction process. This report describes those results and is written in completion of milestone M3FT-16IN030102028, the goal of which was to evaluate the role of organic acids in the protection of ligands from radiolytic degradation. 


\section{CONTENTS}

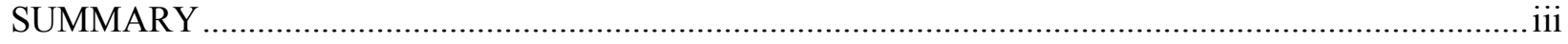

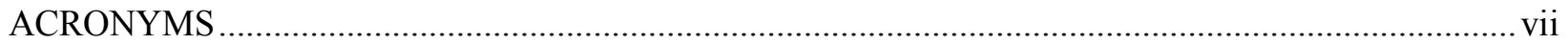

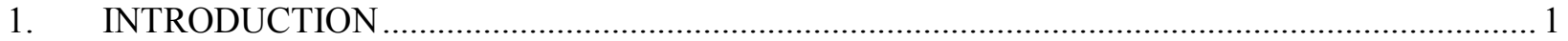

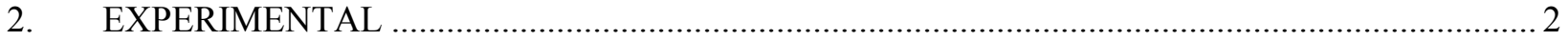

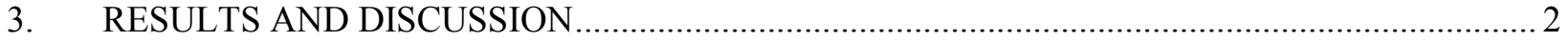

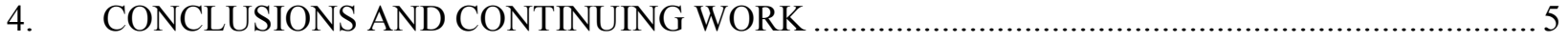

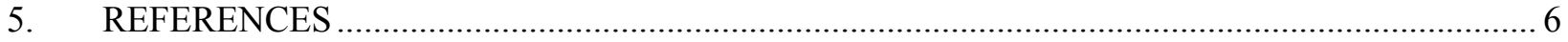




\section{FIGURES}

Figure 1. Top: Transient kinetic data for $(\mathrm{SCN})_{2}{ }^{-\bullet}$ transient absorbance measured at $475 \mathrm{~nm}$ at $22.4^{\circ} \mathrm{C}$ and $\mathrm{pH}$ 4.657. From top to bottom curves depict individual profiles for zero, $1.19 \mathrm{mM}, 2.08 \mathrm{mM}, 3.05 \mathrm{mM}, 4.10 \mathrm{mM}$ and $5.00 \mathrm{mM}$ added citric acid. Bottom: transformed competition kinetics data from peak intensities of individual curves shown in top plot. Solid line is weighted linear fit, with slope of $(1.000 \pm 0.018) \times 10^{-2}, \mathrm{R}^{2}=$ 0.999. This slope corresponds to an overall rate constant of $\mathrm{k}_{2}=(1.143 \pm 0.021) \times 10^{8}$ $\mathrm{M}^{-1} \mathrm{~s}^{-1}$ under these conditions. 


\section{TABLES}

Table 1. Rate constants for the H-atom abstraction by hydroxyl radical for several aminopolycarboxylic and carboxyl acids.

Table 2. Calculated citrate speciation and values of kmeas for different solution $\mathrm{pH}$ values..................... 4

Table 3. Values of the individual k' rate constants for the reaction of hydroxyl radical with citric acid. 


\section{ACRONYMS}

CA Citric acid

DTPA Diethylenetriaminepentaacetic acid

FCR\&D Fuel Cycle Research and Development program

HDEHP Bis(2-ethylhexyl)phosphoric acid

HEDTA N-(2-hydroxyethyl)ethylenediamine-N,N',N'-triacetic acid

HEH[EHP] 2-ethyl(hexyl)phosphonic acid mono-2-ethylhexyl ester

INL Idaho National Laboratory

LA Lactic Acid

$\mathrm{SCN}^{-} \quad$ Thiocyanate anion

TALSPEAK Trivalent Actinide Lanthanide Separation by Phosphorous reagent Extraction from Aqueous Komplexes

TRUEX TRansUranic EXtraction process 



\section{EVALUATE THE ROLE OF ORGANIC ACIDS IN THE PROTECTION OF LIGANDS FROM RADIOLYTIC DEGRADATION}

\section{INTRODUCTION}

Separating the minor actinide elements (americium and curium) from the fission product lanthanides is an important step in closing the nuclear fuel cycle. Isolating the minor actinides will allow transmuting them to short lived or stable isotopes in fast reactors, thereby reducing the long-term hazard associated with these elements. ${ }^{1}$ A two-step method is being considered by the Fuel Cycle Research and Development (FCR\&D) program to separate the minor actinides from acidic high-level waste. The first step involves co-extracting the lanthanides and minor actinides using the transuranic extraction (TRUEX) process. $^{2}$ The second step uses the Trivalent Actinide-Lanthanide Separations by Phosphorus-reagent Extraction from Aqueous Complexes (TALSPEAK) process to separate the minor actinides from the lanthanides. ${ }^{3}$ The tandem TRUEX-TALSPEAK approach has been demonstrated on irradiated fuel at a laboratory scale. ${ }^{4}$ However, the TALSPEAK process suffers the disadvantage of slow extraction and stripping kinetics and high sensitivity to the aqueous phase $\mathrm{pH}$. To overcome these disadvantages, a variation of the TALSPEAK process has been proposed which replaces the traditionally used bis(2ethylhexyl)phosphoric acid (HDEHP) extractant with 2-ethylhexylphosphonic acid mono-2-ethylhexyl ester (HEH[EHP]). ${ }^{5}$ In addition, the aqueous phase complexant and buffer used in traditional TALSPEAK are replaced with the combination of $\mathrm{N}$-(2-hydroxyethyl)ethylenediamine-N,N',N'-triacetic acid (HEDTA) and citric acid. This is referred to as the Advanced TALSPEAK process. The key advantages of Advanced TALSPEAK process are reported to be less dependence of the process performance on the aqueous solution $\mathrm{pH}$, more predictable extraction behavior, and more rapid extraction kinetics. The structures of the compounds utilized in this process are shown in Figure 1.

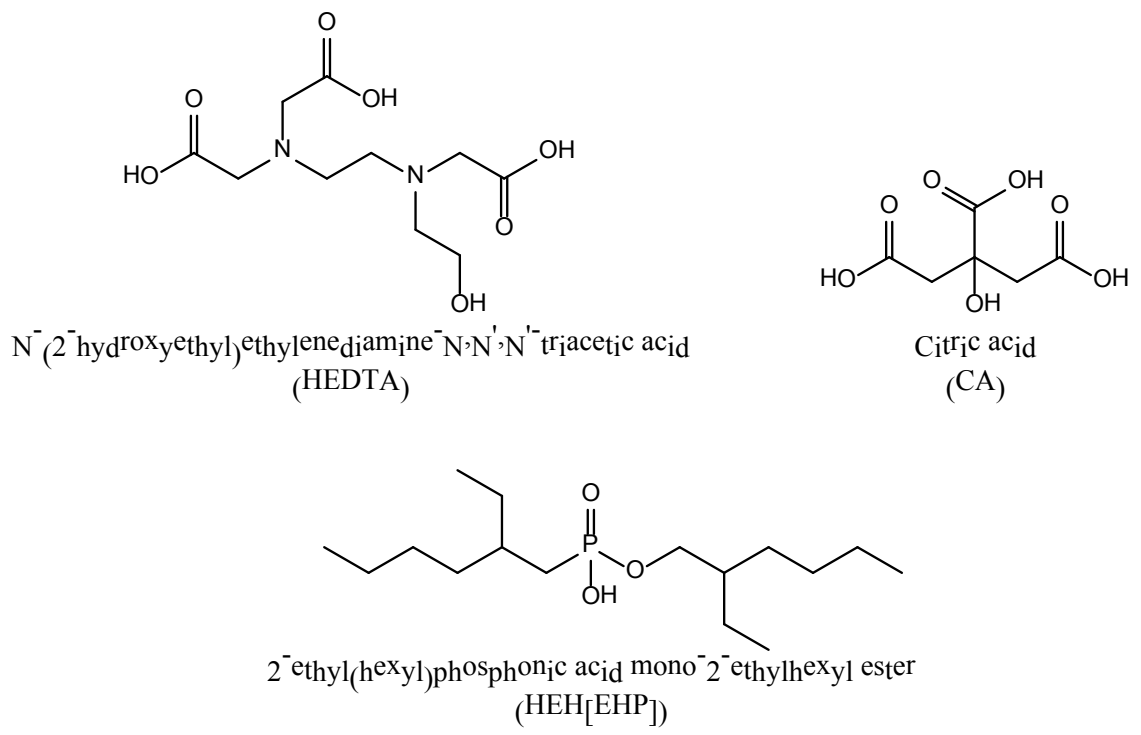

Figure 1. Structures of compounds used in the Advanced TALSPEAK process.

In order to evaluate the possible impacts of radiation damage upon the efficacy of the Advanced TALSPEAK flowsheet, aqueous and organic phases corresponding to the extraction section of the proposed flowsheet were irradiated in the INL test loop under an ambient atmosphere and by air-sparged static irradiations. A suite of analytical techniques were employed to determine the variation in composition as a function of absorbed $\gamma$-dose and in some cases identify the radiolytically produced 
species. Samples of the irradiated aqueous and organic phases were spiked with americium and europium radiotracers and distribution ratios $\left(\mathrm{D}_{\mathrm{Am}}\right.$ and $\left.\mathrm{D}_{\mathrm{Eu}}\right)$ were determined as a function of absorbed dose. ${ }^{6}$

Results from this earlier study performed at the $\mathrm{INL}^{7}$ suggested that different carboxylic acid buffers employed in the TALSPEAK and Advanced TALSPEAK process chemistries (citric acid versus lactic acid) lead to differing extents of radiolytic degradation of the aminopolycarboxylate (HEDTA) aqueous soluble complexant. Based upon those observations, the rate of reaction of hydroxyl radical with citric acid was measured. This report describes those results and is written in completion of milestone M3FT16IN030102028, the goal of which was to evaluate the role of organic acids in the protection of ligands from radiolytic degradation.

\section{EXPERIMENTAL}

All chemicals (Aldrich) used in the study were reagent grade or higher and used as received without further purification. Solutions were made with ultrapure deionized water $(\geq 18 \mathrm{M} \Omega$ ) obtained from a Millipore Milli-Q system.

The measurements of hydroxyl radical reaction rate constants were performed using the linear accelerator (LINAC) electron pulse radiolysis system at the Radiation Laboratory, University of Notre Dame. The irradiation and transient absorption detection system has been described elsewhere. ${ }^{8}$ Dosimetry ${ }^{9}$ was performed on $\mathrm{N}_{2} \mathrm{O}$ saturated solutions of $\operatorname{KSCN}\left(1.00 \times 10^{-2} \mathrm{M}\right)$ at $\lambda=475 \mathrm{~nm}(G \varepsilon=5.2$ $\left.\mathrm{x} 10^{-4} \mathrm{~m}^{2} \mathrm{~J}^{-1}\right)$, with an average dose of $3-5$ Gy per $2-3$ ns pulse.

Temperature control of the solutions was achieved by flowing the ambient temperature solutions through a short temperature controlled condenser prior to irradiation. The solution temperature was measured immediately post irradiation using a thermocouple placed directly in the flow. ${ }^{10}$ Temperature stability of this system was $\pm 0.3^{\circ} \mathrm{C}$.

\section{RESULTS AND DISCUSSION}

For the $\gamma$-radiolysis of acidic (nitric acid) aqueous and organic (paraffinic) mixtures, the hydroxyl radical is the predominate radical species present in solution. ${ }^{11}$ The primary mode of interaction between hydroxyl radical and aminopolycarboxylic and carboxylic acids is $\mathrm{H}$-atom abstraction from the ligand. The rate constants for $\mathrm{H}$-atom abstraction, $\mathrm{k}$, by hydroxyl radica ${ }^{12}$ for compounds relevant to the TALSPEAK and Advanced TALSPEAK, ALSEP processes are listed in Table 1. The majority of these rate constants listed in Table 1 were not obtained under process relevant conditions.

Table 1. Rate constants for the H-atom abstraction by hydroxyl radical for several aminopolycarboxylic and carboxyl acids.

\begin{tabular}{|c|c|}
\hline Species & $\mathrm{k}, \mathrm{L} \cdot \mathrm{mol}^{-1} \cdot \mathrm{s}^{-1}$ \\
\hline EDTA $^{2-}, \mathrm{pH}=4$ & $4.0 \times 10^{8}$ \\
\hline EDTA $^{3-}, \mathrm{pH}=9$ & $2.0 \times 10^{9}$ \\
\hline DTPA, $\mathrm{pH} \sim 7$ & $2.3 \times 10^{9}$ \\
\hline HEDTA, $\mathrm{pH} \sim 0$ & $1.1 \times 10^{10}$ \\
\hline Citric acid, $\mathrm{pH} \sim 1$ & $5.0 \times 10^{7}$ \\
\hline Lactic acid, $\mathrm{pH} \sim 1$ & $4.3 \times 10^{8}$ \\
\hline
\end{tabular}

From the values listed in Table 1, it is clear that aminopolycarboxylic acids react rapidly with hydroxyl radical. In the case of HEDTA, the rate of reaction with hydroxyl radical is essentially diffusion 
controlled. Carboxylic acids react more slowly with hydroxyl radical in solution. A relative rate analysis for the TALSPEAK and Advanced TALSPEAK systems shows the rate of reaction of lactic acid (LA) with hydroxyl radical is approximately 65 times faster than the rate of reaction of citric acid (CA) with hydroxyl radical (1.5 M LA x $\mathrm{k}_{\mathrm{LA}}$ versus $0.2 \mathrm{M} \mathrm{CA} \times \mathrm{k}_{\mathrm{CA}}$ ). The higher relative rate calculated for the TALSPEAK system indicates the high concentration of LA may serve to protect the TALSPEAK solvent from radiolytic degradation by acting as a hydroxyl radical scavenger. The slower rate of reaction for citric acid with the hydroxyl radical and the lower concentration of the carboxylic acid buffer used in the Advanced TALSPEAK process likely accounts for the observed significant increase in $D_{A m}$ versus absorbed dose. $^{7}$ This can be attributed to a decrease in HEDTA concentration caused by its reaction with hydroxyl radical; since HEDTA functions as an actinide "holdback" reagent, the consumption of HEDTA by H-atom abstraction by the hydroxyl radical results in higher $\mathrm{D}_{\mathrm{Am}}$ and lower ${ }^{\text {Eu }} \mathrm{S}_{\mathrm{Am}}$ values.

In order to gain a more detailed understanding the rates of reactions important to the Advanced TALSPEAK process, the rate of reaction of hydroxyl radical with citric acid was measured under process relevant conditions. The kinetics of this reaction were explored by competitive methods using KSCN as a standard; whose rate constant ${ }^{12}$ has been well-established as a function of temperature. At $25^{\circ} \mathrm{C}$ this reaction is:

$$
\cdot \mathrm{OH}+\mathrm{SCN}^{-}\left(+\mathrm{SCN}^{-}\right) \rightarrow(\mathrm{SCN})_{2}^{-\bullet}+\mathrm{OH}^{-} \quad \mathrm{k}_{1}=1.15 \times 10^{10} \mathrm{M}^{-1} \mathrm{~s}^{-1}
$$

Typical kinetic data are shown in Figure 1. It is seen that with the addition of citric acid, the $(\mathrm{SCN})_{2}{ }^{-}$ absorbance intensity at $475 \mathrm{~nm}$ decreases (Figure 1 top). By analyzing the reaction

$$
\cdot \mathrm{OH}+\text { citric acid } \rightarrow \text { products } \quad \mathrm{k}_{2}=?
$$

in competition with the hydroxyl radical reaction with thiocyanate we obtain the expression:

$$
\frac{A b s^{o}}{A b s}=1+\frac{k_{2}[C A]}{k_{1}\left[S C N^{-}\right]}
$$

where $\mathrm{Abs}^{\circ}$ is the transient absorbance in the absence of any added citric acid, and Abs is the reduced absorbance in its presence. The transformed linear plot of $\mathrm{Abs}^{\circ} / \mathrm{Abs}$ vs. [CA]/[SCN $\mathrm{SC}^{-}$is seen in Figure 1 (bottom). From the linear fit to these data, we obtain an overall rate constant of $\mathrm{k}_{2}=(1.14 \pm 0.02) \times 10^{8}$ $\mathrm{M}^{-1} \mathrm{~s}^{-1}$. 

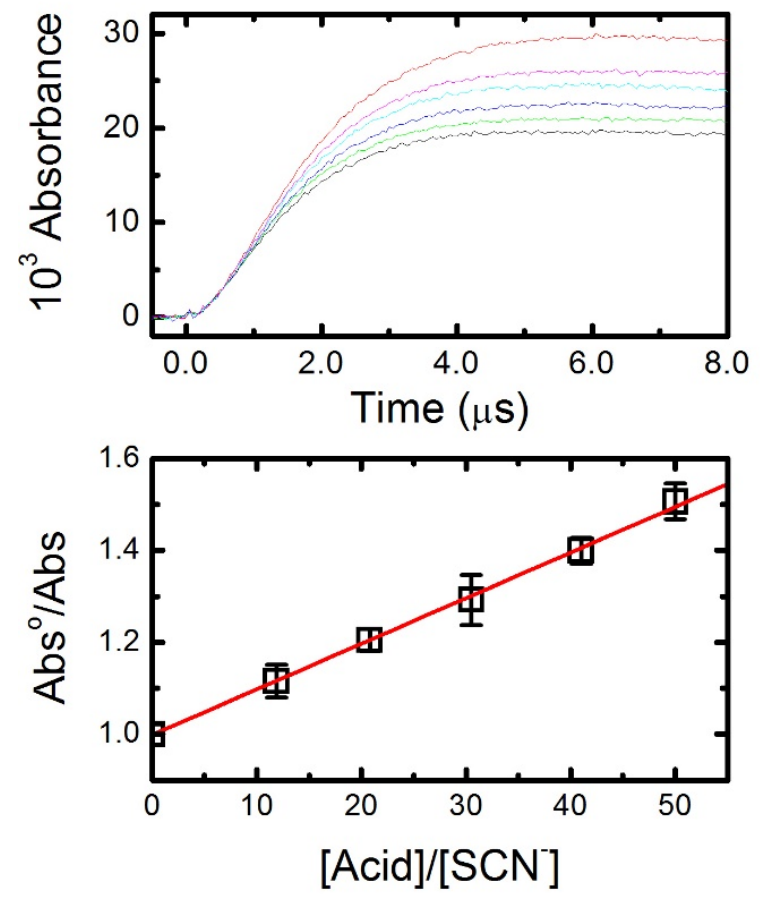

Figure 1. Top: Transient kinetic data for $(\mathrm{SCN})_{2}^{-\bullet}$ transient absorbance measured at 475 $\mathrm{nm}$ at $22.4^{\circ} \mathrm{C}$ and $\mathrm{pH} 4.657$. From top to bottom curves depict individual profiles for zero, 1.19 $\mathrm{mM}, 2.08 \mathrm{mM}, 3.05 \mathrm{mM}, 4.10 \mathrm{mM}$ and $5.00 \mathrm{mM}$ added citric acid. Bottom: transformed competition kinetics data from peak intensities of individual curves shown in top plot. Solid line is weighted linear fit, with slope of $(1.00 \pm 0.02) \mathrm{x}$ $10^{-2}, \mathrm{R}^{2}=1.00$. This slope corresponds to an overall rate constant of $\mathrm{k}_{2}=(1.14 \pm 0.02) \times 10^{8}$ $\mathrm{M}^{-1} \mathrm{~s}^{-1}$ under these conditions.

This rate constant is a composite of 4 different citric acid species as citric acid has three pKa values ${ }^{13}$ of $3.13,4.77$ and 6.39

$$
\mathrm{H}_{3} \mathrm{~A} \leftrightharpoons \mathrm{H}_{2} \mathrm{~A}^{-} \leftrightharpoons \mathrm{HA}^{2-} \leftrightharpoons \mathrm{A}^{3-}
$$

For this $\mathrm{pH}=4.657$, we have fractional species of $\mathrm{f}_{1}=7.86 \mathrm{E}-03, \mathrm{f}_{2}=4.25 \mathrm{E}-01, \mathrm{f}_{3}=5.51 \mathrm{E}-01$, and $\mathrm{f}_{4}=$ $1.64 \mathrm{E}-02$. This allows us to calculate the individual speciation of each species at any $\mathrm{pH}$. It is wellassumed that the measured over-all rate constant is a sum of the individual components, where each species will have its own rate constant. Thus at this $\mathrm{pH}, \mathrm{k}_{\text {meas }}$ may be expressed as:

$$
\mathrm{k}_{\text {meas }}=\mathrm{k}_{1}{ }_{1}(7.86 \mathrm{E}-03)+\mathrm{k}_{2}{ }_{2}(4.25 \mathrm{E}-01)+\mathrm{k}_{3}{ }_{3}(5.51 \mathrm{E}-01)+\mathrm{k}_{4}(1.64 \mathrm{E}-02)
$$

By determining values of $\mathrm{k}_{\text {meas }}$ at four different solution $\mathrm{pH}$ values, individual rate constants for each citric acid species may be calculated. A typical data set is shown in Table 2.

\begin{tabular}{|c|c|c|c|c|c|c|c|}
\hline pH & f1 & f2 & f3 & f4 & $\begin{array}{l}\text { Rate } \\
\text { const }\end{array}$ & $\begin{array}{l}\mathbf{k}_{\text {meas }} \\
\mathbf{M}^{-1} \mathbf{s}^{-1} \\
\end{array}$ & Error \\
\hline 3.330 & 1.90E-05 & $2.18 \mathrm{E}-02$ & 6.00E-01 & 3.78E-01 & $\mathbf{k}_{1}$ & $7.81 \times 10^{7}$ & $4.11 \times 10^{6}$ \\
\hline 3.820 & $2.29 E-04$ & $8.52 \mathrm{E}-02$ & 7.59E-01 & $1.55 \mathrm{E}-01$ & $\mathbf{k}_{2}$ & $8.36 \times 10^{7}$ & $4.41 \times 10^{6}$ \\
\hline 4.657 & 7.86E-03 & $4.25 E-01$ & $5.51 \mathrm{E}-01$ & 1.64E-02 & $\mathbf{k}_{3}$ & $1.14 \times 10^{8}$ & $2.11 \times 10^{6}$ \\
\hline 6.387 & 4.92E-01 & 4.96E-01 & 1.20E-02 & 6.63E-06 & $\mathbf{k}_{4}$ & $2.19 \times 10^{8}$ & $6.34 \times 10^{6}$ \\
\hline
\end{tabular}

Table 2. Calculated citrate speciation and values of kmeas for different solution $\mathrm{pH}$ values.

The values in blue (in Table 2) form a 4 x 4 matrix that can be inverted, and then pre-multipled by the $\mathrm{k}_{\text {meas }}$ values to give the individual k' rate constants. The individual $\mathrm{k}$ ' rate constants for the reaction of hydroxyl radical with citric acid determined in this work are shown in Table 3. 
Table 3. Values of the individual k' rate constants for the reaction of hydroxyl radical with citric acid.

\begin{tabular}{|c|c|}
\hline Rate constant & $\begin{array}{c}\text { Calculated value } \\
\mathbf{M}^{-1} \mathbf{s}^{-\mathbf{1}}\end{array}$ \\
\hline $\mathbf{k}^{\prime}{ }_{\mathbf{1}}$ & $7.65 \times 10^{7}$ \\
\hline $\mathbf{k}_{\mathbf{2}}$ & $7.61 \times 10^{7}$ \\
\hline $\mathbf{k}_{\mathbf{3}}$ & $1.62 \times 10^{8}$ \\
\hline $\mathbf{k}_{\mathbf{4}}$ & $2.80 \times 10^{8}$ \\
\hline
\end{tabular}

The value of $\mathrm{k}_{1}=7.65 \mathrm{x}^{1}$ (determined at $\mathrm{pH}=3.33$ ) agrees fairly well with the rate constant reported $\left(5.0 \times 10^{7} \mathrm{M}^{-1} \mathrm{~s}^{-1}\right)$ by Buxton et al. (determined at $\left.\mathrm{pH} \sim 1\right),{ }^{12}$ however, it is approximately a factor of two higher than the value reported by Anbar and Neta ${ }^{14}$ of $3.0 \times 10^{7} \mathrm{M}^{-1} \mathrm{~s}^{-1}$. Interestingly, the reaction rate determined for citric using a solution $\mathrm{pH}$ relevant to actual process conditions is approximately an order of magnitude slower than the hydroxyl radical reaction rate determined by Martin et al. for lactic acid using TALSPEAK process conditions $\left(7.77 \times 10^{8} \mathrm{M}^{-1} \mathrm{~s}^{-1}\right)$. Since the TALSPEAK, Advanced TALSPEAK, and ALSEP stripping sections are operated at a $\mathrm{pH}$ in the range of $3-4$, these recent rate constant determinations demonstrate the importance of measuring these reaction rates under process relevant conditions.

\section{CONCLUSIONS AND CONTINUING WORK}

In the Advanced TALSPEAK process, the bis(2-ethylhexyl)phosphoric acid (HDEHP) extractant used in the traditional TALSPEAK process is replaced by the extractant 2-ethylhexylphosphonic acid mono-2-ethylhexyl ester (HEH[[EHP]). In addition, the aqueous phase complexant and buffer used in traditional TALSPEAK is replaced with the combination of N-(2-hydroxyethyl)ethylenediamineN,N',N'-triacetic acid (HEDTA) and citric acid. In order to evaluate the possible impacts of gamma radiolysis upon the efficacy of the Advanced TALSPEAK flowsheet, aqueous and organic phases corresponding to the extraction section of the proposed flowsheet were irradiated in the INL test loop under an ambient atmosphere.

The variation in the rate constants for the reaction of hydroxyl radical with different aminopolycarboxylates and carboxylic acids can account for the differences observed for the irradiation of the TALSPEAK and Advanced TALSPEAK solvent systems. The results of these studies conducted at INL, led INL researchers to conclude that the scarcity of values of rate constants for the reaction of hydroxyl radical with the components of the Advanced TALSPEAK process chemistry was severely limiting the interpretation of the results of radiolysis studies performed at the INL. In this work, the rate of reaction of hydroxyl radical with citric acid at several $\mathrm{pH}$ values was measured using a competitive pulse radiolysis technique. The results reported here demonstrate the importance of obtaining hydroxyl radical reaction rate data for the conditions that closely resemble actual solution conditions expected to be used in an actual solvent extraction process.

Continuing work will focus on the use laser flash photolysis for the determination of hydroxyl radical reaction rates with carboxylic and aminopolycarboxylic acids. The limited availability of the LINAC at the Radiation Laboratory, University of Notre Dame has driven the program to acquire a laser flash photolysis apparatus at INL. The rates of reaction of lactic, citric, and malonic acids will be measured using the competitive KSCN technique. Attempts will also be made to measure aminopolycarboxylic acid rates of reaction. However, the UV absorption of this class of compounds may necessitate the use of the pulse radiolysis technique. 


\section{REFERENCES}

1. (a) Hudson, M. J.; Harwood, L. M.; Laventine, D. M.; Lewis, F. W., Use of Soft Heterocyclic NDonor Ligands To Separate Actinides and Lanthanides. Inorganic Chemistry 2013, 52, 3414-3428; (b) Todd, T. A., Separation Research for Advanced Nuclear Fuel Cycles. In Nuclear Energy and the Environment, Wai, C. M.; Mincher, B. J., Eds. American Chemical Society: Washington, D.C., 2010; pp 13-18.

2. Horwitz, E. P.; Kalina, D. G.; Diamond, H.; Vandegrift, G. F.; Schulz, W. W., The TRUEX Process A Process for the Extraction of the Transuranic Elements from Nitric Acid Wastes Utilizing Modified PUREX Solvent. Solvent Extraction and Ion Exchange 1985, 3, 75-109.

3. (a) Weaver, B.; Kappelmann, F. A., Preferential extraction of lanthanides over trivalent actinides by monoacidic organophosphates from carboxylic acids and from mixtures of carboxylic and aminopolyacetic acids. J. Inorg. Nucl. Chem. 1968, 30, 263-272; (b) Nilsson, M.; Nash, K. L., Review Article: A Review of the Development and Operational Characteristics of the TALSPEAK Process. Solvent Extraction and Ion Exchange 2007, 25, 665-701.

4. Pereira, C.; Vandegrift, G. F.; Regalbuto, M. C.; Bakel, A.; Bowers, D.; Gelis, A. V.; Hebden, A. S. M., L. E. ; Stepinski, D.; Tsai, Y.; Laidler, J. J. In Lab-Scale Demonstration of the UREX+1a Process Using Spent Nuclear Fuel, Waste Management 2007, Tucson, AZ, February 25 - March 1, 2007; Tucson, AZ, 2007.

5. Braley, J. C.; Grimes, T. S.; Nash, K. L., Alternatives to HDEHP and DTPA for Simplified TALSPEAK Separations. Industrial \& Engineering Chemistry Research 2011, 51, 629-638.

6. Peterman, D. R.; Olson, L. G.; McDowell, R. G.; Groenewold, G. S.; Zarzana, C. A.; Bauer, W. F.; Morgan, S. J. Investigation of the Impacts of Gamma Radiolysis on an Advanced TALSPEAK Separation; INL/CON-14-32597; Idaho National Laboratory: Idaho Falls, ID, August 15, 2014.

7. Zarzana, C. A.; Peterman, D. R.; Groenewold, G. S.; Olson, L. G.; McDowell, R. G.; Bauer, W. F.; Morgan, S. J., Investigation of the Impacts of Gamma Radiolysis on an Advanced TALSPEAK Separation. Separation Science and Technology 2015, 2836-2843.

8. Whitman, K.; Lyons, S.; Miller, R.; Nett, D.; Treas, P.; Zante, A.; Fessenden, R. W.; Thomas, M. D.; Wang, Y. In Linear Accelerator For Radiation Chemistry Research at Notre Dame, IEEE Proceedings Particle Accelerator Conference and International Conference on High Energy Accelerators, Dallas, TX, IEEE: Dallas, TX, 1995; pp 131-133.

9. Buxton, G. V.; Stuart, C. R., Re-evaluation of the thiocyanate dosimeter for pulse radiolysis. Journal of the Chemical Society, Faraday Transactions 1995, 91, 279-281.

10. Mezyk, S. P.; Madden, K. P., Arrhenius Parameter Determination for the Reaction of Methyl Radicals with Iodine Species in Aqueous Solution. The Journal of Physical Chemistry 1996, 100 (22), 93609364.

11. Mincher, B. J.; Mezyk, S. P., Radiation chemcial effects on radiochemistry: A review of examples important to nuclear power. Radiochimica Acta 2009, 97, 519-534. 
12. Buxton, G. V.; Greenstock, C. L.; Helman, W. P.; Ross, A. B., Critical review of rate constants for reactions of hydrated electrons, hydrogen atoms and hydroxyl radicals $\left(\cdot \mathrm{OH} / \cdot \mathrm{O}^{-}\right)$in aqueous solution. Journal of Physical and Chemical Reference Data 1988, 17, 513-886.

13. (a) Bates, R. G.; Pinching, G. D., Resolution of the Dissociation Constants of Citric Acid at 0 to $50^{\circ}$, and Determination of Certain Related Thermodynamic Functions. Journal of the American Chemical Society 1949, 71, 1274-1283; (b) Brown, M. A.; Kropf, A. J.; Paulenova, A.; Gelis, A. V., Aqueous complexation of citrate with neodymium(III) and americium(III): a study by potentiometry, absorption spectrophotometry, microcalorimetry, and XAFS. Dalton Transactions 2014, 43, 64466454.

14. Anbar, M.; Neta, P., A compilation of specific bimolecular rate constants for the reactions of hydrated electrons, hydrogen atoms and hydroxyl radicals with inorganic and organic compounds in aqueous solution. The International Journal of Applied Radiation and Isotopes 1967, 18, 493-523. 